\title{
Alterations in Brain Metabolites in Patients with Epilepsy with Impaired Consciousness: A Case-Control Study of Interictal Multivoxel 'H-MRS Findings
}

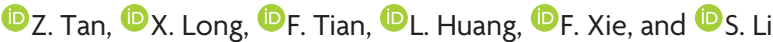

\begin{abstract}
BACKGROUND AND PURPOSE: Previous studies have shown perfusion abnormalities in the thalamus and upper brain stem in patients with epilepsy with impaired consciousness. We hypothesized that these areas associated with consciousness will also show metabolic abnormalities. However, metabolic abnormalities in those areas correlated with consciousness has not been characterized with multiplevoxel ' $\mathrm{H}$-MRS. In this study, we investigated the metabolic alterations in these brain regions and assessed the correlation between seizure features and metabolic alterations.
\end{abstract}

MATERIALS AND METHODS: Fifty-seven patients with epilepsy and 24 control subjects underwent routine MR imaging and 3D multiplevoxel ' $\mathrm{H}$-MRS. Patients were divided into 3 subgroups: focal impaired awareness seizures $(n=18)$, primary generalized tonic-clonic seizures $(n=19)$, and secondary generalized tonic-clonic seizures $(n=20)$. The measured metabolite alterations in NAA/Cr, NAA/(Cr $+\mathrm{Cho})$, and $\mathrm{Cho} / \mathrm{Cr}$ ratios in brain regions associated with the consciousness network were compared between the patient and control groups. ROls were placed in the bilateral inferior frontal gyrus, supramarginal gyrus, cingulate gyrus, precuneus, thalamus, and upper brain stem. Correlations between clinical parameters (epilepsy duration and seizure frequency) and metabolite alterations were analyzed.

RESULTS: Significantly lower NAA/Cr and NAA/(Cho $+\mathrm{Cr}$ ) ratios $(P<.05$ and $<.01$, respectively) were observed in the bilateral thalamus and upper brain stem in all experimental groups, and significantly high Cho/Cr ratios $(P<.05)$ were observed in the right thalamus in the focal impaired awareness seizures group. There were no significant differences in metabolite ratios among the 3 patient groups $(P>.05)$. The secondary generalized tonic-clonic seizures group showed a negative correlation between the duration of epilepsy and the NAA/ $(\mathrm{Cr}+\mathrm{Cho})$ ratio in the bilateral thalamus $(P<.05)$.

CONCLUSIONS: Metabolic alterations were observed in the brain stem and thalamus in patients with epilepsy with impaired consciousness.

ABBREVIATIONS: FIAS = focal impaired awareness seizures; PGTCS = primary generalized tonic-clonic seizures; SGTCS = secondary generalized tonic-clonic seizures

E pilepsy is a devastating illness of the nervous system. Studies have shown that uncontrolled seizures impair the quality of life of patients with epilepsy, particularly those who have seizures with impaired consciousness. ${ }^{1,2}$ Impaired consciousness during seizure episodes may have adverse consequences, such as accidental injuries or even death. Given its potential hazards, investigation of the underlying mechanisms of impaired consciousness during seizures is imperative.

Received June 28, 2018; accepted after revision December 1.

From the Departments of Neurology (Z.T., X.L., F.T., L.H., S.L.) and Radiology (F.X.),

Xiangya Hospital, Central South University, Changsha, China.

Zheren Tan and Xiaoyan Long contributed equally to this work.

Please address correspondence to Shuyu Li, MD, Central South University, Department of Neurology, 87 Xiangya Rd, Changsha 410008, China; e-mail:

xysnlsy@sina.com/409685656@qq.com

http://dx.doi.org/10.3174/ajnr.A5944
With rapid advances in neuroimaging technology and knowledge of brain electrophysiology, structural and functional alterations in some specific areas of the brain have been shown to be associated with the status of consciousness in the course of focal impaired awareness seizures (FIAS) and generalized tonic-clonic seizures. ${ }^{3-5}$ These specific structures constitute the consciousness system, ${ }^{6-8}$ including the bilateral medial and lateral frontoparietal association cortex and subcortical arousal systems.

Blumenfeld et $\mathrm{al}^{9}$ reported widespread bilateral cerebral blood flow alterations in the course of human FIAS arising from the temporal lobe; they suggested that impaired consciousness during temporal lobe seizures may result from focal abnormal activity in the temporal and subcortical networks linked to widespread impaired function of the association cortex, as assessed by SPECT and electroencephalography. Lee et $\mathrm{al}^{10}$ have shown perfusion alterations in the bilateral thalamus and upper brain stem in patients with epilepsy 
with impaired consciousness using SPECT. Marie et $\mathrm{al}^{11}$ reported that impaired consciousness during temporal lobe seizures is characterized by increased long-distance synchronization between the thalamus and parietal cortices based on stereoelectroencephalography. Xie et $\mathrm{al}^{12}$ used DTI to demonstrate long-lasting neuronal dysfunction of the bilateral dorsal thalamus and posterosuperior aspect of the midbrain in patients with epilepsy.

${ }^{1} \mathrm{H}-\mathrm{MR}$ spectroscopy is a noninvasive MR imaging technique that can detect NAA, Cho, Cr, and other metabolites in brain tissues. ${ }^{13-20}$ Previous studies have confirmed hippocampal metabolic alterations in patients with temporal lobe epilepsy by ${ }^{1} \mathrm{H}$ MRS. ${ }^{15,21}$ Therefore, we hypothesized that the areas associated with consciousness may also show metabolic alterations in patients with epilepsy with impaired consciousness. However, the metabolic alterations in these brain regions of patients with epilepsy have not been characterized with multiple-voxel ${ }^{1} \mathrm{H}-\mathrm{MR}$ spectroscopy. In the present study, we evaluated the specific brain regions of patients with epilepsy for metabolic alterations using multivoxel ${ }^{1} \mathrm{H}-\mathrm{MRS}$ and assessed the correlation between seizure features and metabolic alterations.

\section{MATERIALS AND METHODS}

\section{Participants}

This study was conducted at the Xiangya Hospital, Central South University, Changsha, China, from August 2011 to January 2012. All patients were diagnosed with epilepsy at the Department of Neurology. The inclusion criteria were the following: 1) patients with a confirmed diagnosis of epilepsy based on clinical assessment, neuroimaging, and electroencephalography (using the latest criteria of the International League Against Epilepsy for classification of seizures ${ }^{22}$ ); 2) the availability of complete clinical data and interictal MR imaging/MR spectroscopy findings; 3 ) a history of loss of consciousness during seizures; 4 ) $\geq 2$ seizure episodes per year; and 5) right-handed patients with no abnormal MR imaging findings. The exclusion criteria were the following: 1) patients with a history of diseases that can affect consciousness, such as syncope, neuropsychiatric disorders, and transient ischemic attacks; 2) patients with serious systemic diseases or metabolic disorders; 3 ) patients with conditions that are contraindications for MR imaging; and 4) patients who refused to undergo ${ }^{1} \mathrm{H}$-MRS.

Not all seizures are associated with loss of consciousness. Seizure types associated with impaired consciousness include absence seizures, focal impaired awareness seizures, and secondary generalized tonic-clonic seizures (SGTCS) ${ }^{6}$; the last type includes primary generalized tonic-clonic seizures (PGTCS) and SGTCSs. All 3 seizure types converge on a common set of structures, including the frontoparietal association cortex and the subcortical arousal systems in the thalamus and upper brain stem, which seem to be vital centers for loss of consciousness in epilepsy. ${ }^{6}$ However, the number of patients diagnosed with absence seizures at the Xiangya Hospital who fulfilled the inclusion criteria was relatively small; therefore, only data pertaining to patients with FIAS, PGTCS, and SGTCS were collected. A total of 57 patients were included in the present study and were divided into 3 groups: FIAS ( $n=18$; mean age, $28 \pm 10$ years); SGTCS $(n=20$; mean age, $27 \pm 13$ years), and PGTCS $(n=19$; mean age, $26 \pm 10$ years). The antiepileptic drugs received by the patients included oxcarbazepine, valproic acid, and levetiracetam. Twenty-four age-, sex-, and handedness-matched healthy subjects ( 16 men, 8 women; mean age, $27 \pm 9$ years) served as the control group. None of the subjects in the control group had any systemic or neurologic illness, history of head trauma, or any family history of neurologic diseases. The protocol for this study was approved by the Research Ethics Committee of the Xiangya Hospital. Written informed consent was obtained from all subjects before their enrollment.

\section{MR Imaging Acquisition}

The study was performed on a Signa HDX 3T MR imaging scanner (GE Healthcare, Milwaukee, Wisconsin); an 8-channel head coil was used for all MR imaging/MR spectroscopy studies. All subjects initially underwent conventional brain MR imaging evaluation. We used the following sequences: axial T1-weighted (TE/ $\mathrm{TR}, 24 / 1750 \mathrm{~ms} ; 384 \times 256$; slice thickness, $5 \mathrm{~mm}$; slice gap, 2 $\mathrm{mm}$ ); axial T2-weighted with fast spin-echo (TE/TR, 120/4480 $\mathrm{ms}$; $384 \times 256$; slice thickness, $5 \mathrm{~mm}$; slice gap $2 \mathrm{~mm}$ ); axial T2 FLAIR (TE/TR, 168/8500 ms; $384 \times 256$; slice thickness, $5 \mathrm{~mm}$; slice gap, $2 \mathrm{~mm}$ ); and sagittal T1-weighted (TE/TR, 24/2650 ms; $384 \times 256$; slice thickness, $5 \mathrm{~mm}$; slice gap, $2 \mathrm{~mm}$ ).

\section{Proton MR Spectroscopy}

3D chemical shift imaging using a point-resolved spectroscopy pulse was performed. To obtain the spectrum, we placed the VOI of the multivoxel MR spectroscopy sections over the brain regions related to the consciousness network. The first multivoxel section (Fig $1 A-H$ ) encompassed the bilateral inferior frontal gyrus, supramarginal gyrus, cingulate gyrus, and precuneus. The second multivoxel section (Fig $1 I,-J$ ) included the bilateral thalamus. The last multivoxel MR spectroscopy section (Fig $1 K$ ) included the upper brain stem. The positioning of the multivoxel sections (3 transverse sections) was performed on voxels graphically prescribed from conventional axial T2-weighted images. Eleven VOIs from 3 sections were obtained. The acquisition parameters used were the following: TE, $144 \mathrm{~ms}$; TR, $1000 \mathrm{~ms}$; NEX, 1.0; FOV, $12 \times 12 \mathrm{~cm}$; phase-encoding matrix, $8 \times 8$; slice thickness, 10 $\mathrm{mm}$; voxel size, $15 \times 15 \times 10 \mathrm{~mm}$; degree of water suppression, $\geq 85 \%$; full width at half maximum, $<10 \mathrm{~Hz}$. The total scan time was 8 minutes and 36 seconds. Water suppression was also applied using the chemical shift selective suppression method.

FuncTool (GE Healthcare) was used to automatically calculate and analyze the integral peak of the corresponding chemical shift of NAA, Cr, and Cho and to measure the metabolite ratios (Figs $1-4)$. Spectra were excluded if they matched the following criteria: 1) water suppression of $<85 \%, 2$ ) full width at half maximum of $\geq 10 \mathrm{~Hz}$, and 3) unstable baseline.

\section{Statistical Analyses}

Data processing and analyses were conducted using SPSS 23.0 for Windows (IBM, Armonk, New York). Continuous variables are expressed as mean $\pm \mathrm{SD}$. To meet the requirements for a normal distribution, we examined each variable independently with a Shapiro-Wilk test. For homogeneity of variance, the Levene test was used. Differences between the patient and control groups with respect to the measured metabolite ratios, including NAA/ $\mathrm{Cr}, \mathrm{NAA} /(\mathrm{Cr}+\mathrm{Cho})$, and $\mathrm{Cho} / \mathrm{Cr}$ of the ROIs, were assessed 


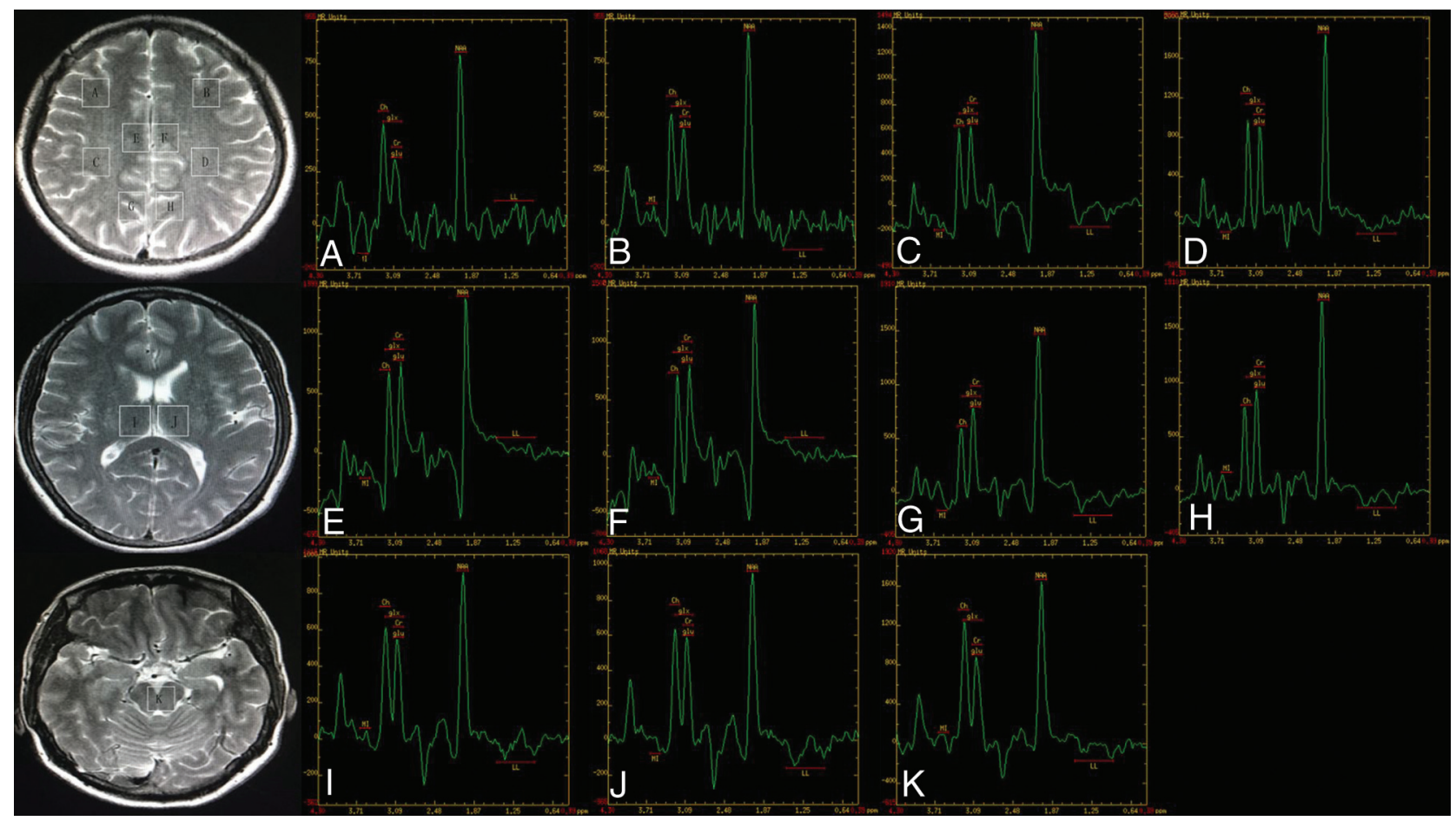

FIG 1. MR spectroscopy maps show the ROIs including the bilateral inferior frontal $(A$ and $B)$, supramarginal gyrus $(C$ and $D)$, cingulate gyrus $(E$ and $F)$, precuneus ( $G$ and $H$ ), thalamus $(I$ and $J)$, and the upper brain stem $(K)$ of a patient with FIAS.

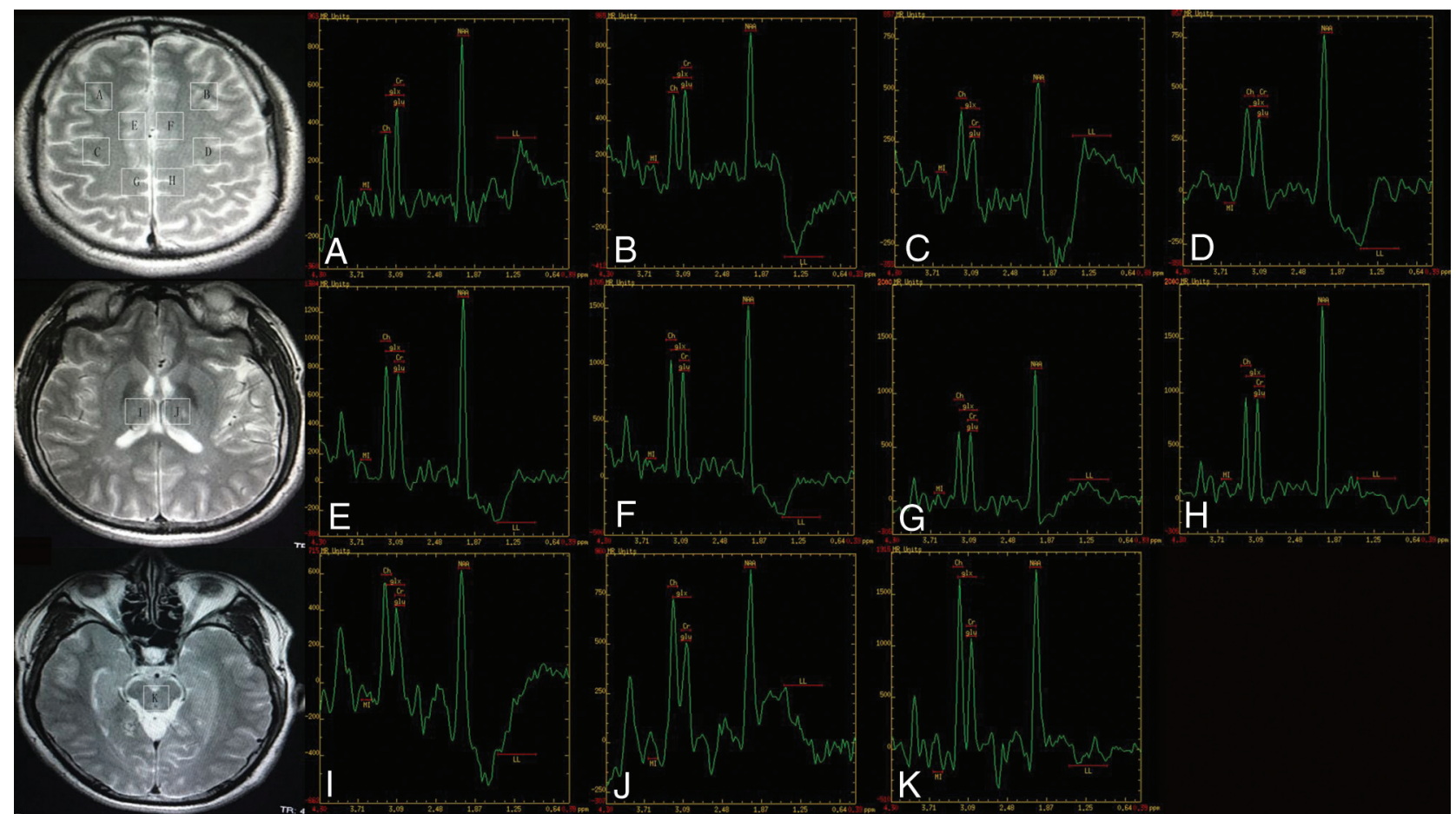

FIG 2. MR spectroscopy maps show the ROls including the bilateral inferior frontal $(A$ and $B)$, supramarginal gyrus $(C$ and $D)$, cingulate gyrus $(E$ and $F$ ), precuneus ( $G$ and $H$ ), thalamus ( $I$ and $J)$, and the upper brain stem $(K)$ of a patient with PGTCS.

using the Kruskal-Wallis ANOVA test. Pair-wise comparisons using the Dunn-Bonferroni approach are presented for any dependent variables for which the Kruskal-Wallis test was significant. Last, the Spearman rank correlation test was performed to explore the correlation between clinical parameters (epilepsy duration and seizure frequency) and corresponding metabolic alterations of patients with 3 different seizure types. $P<.05$ was considered indicative of a significant between-group difference.

\section{RESULTS}

There was no significant difference among the 4 groups with respect to age or sex $(P>.05$ for both). The characteristics of the study 


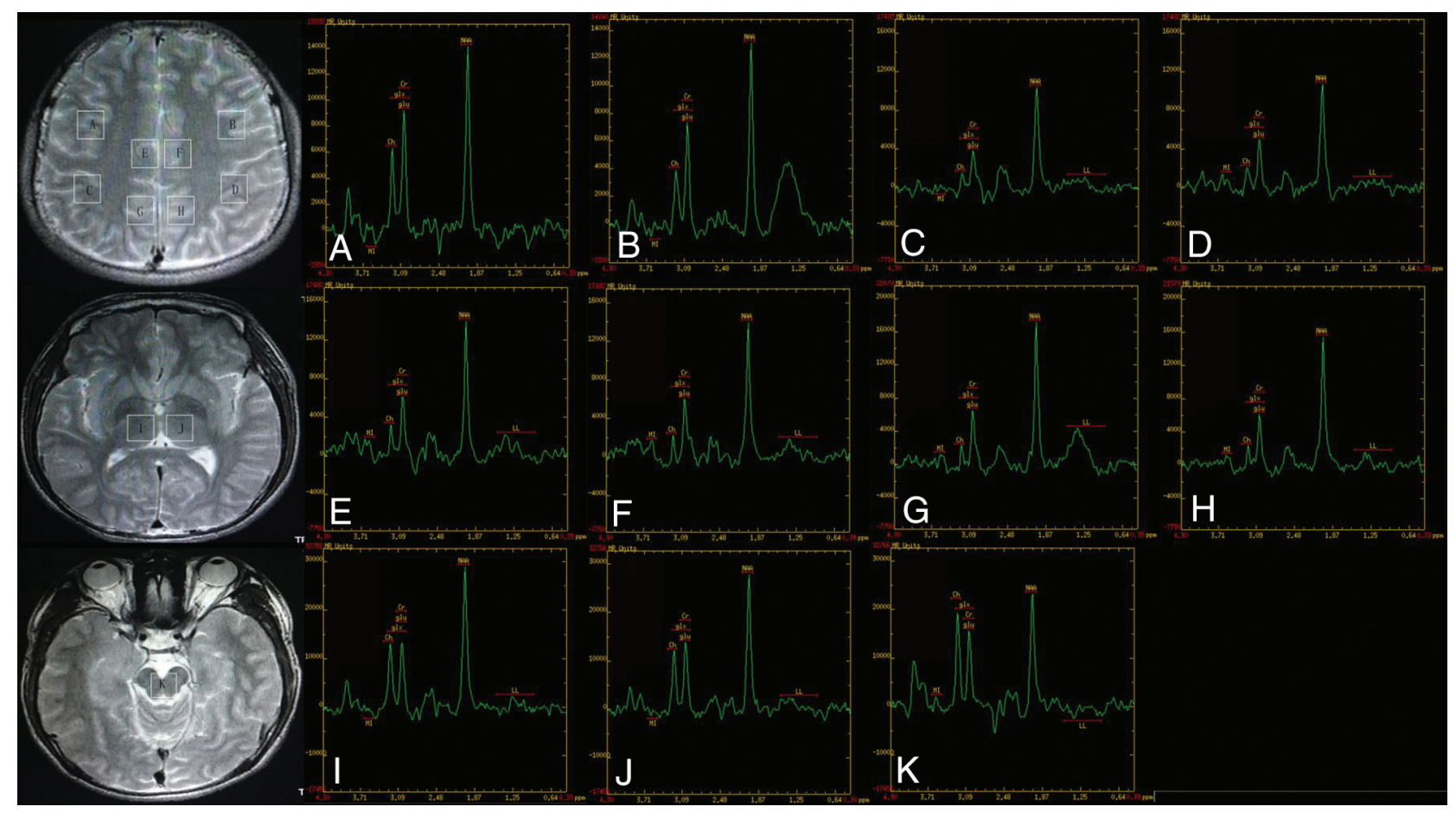

FIG 3. MR spectroscopy maps show the ROls including the bilateral inferior frontal $(A$ and $B)$, supramarginal gyrus $(C$ and $D)$, cingulate gyrus $(E$ and $F$ ), precuneus ( $G$ and $H$ ), thalamus ( $I$ and $/)$, and the upper brain stem $(K)$ of a patient with SGTCS.

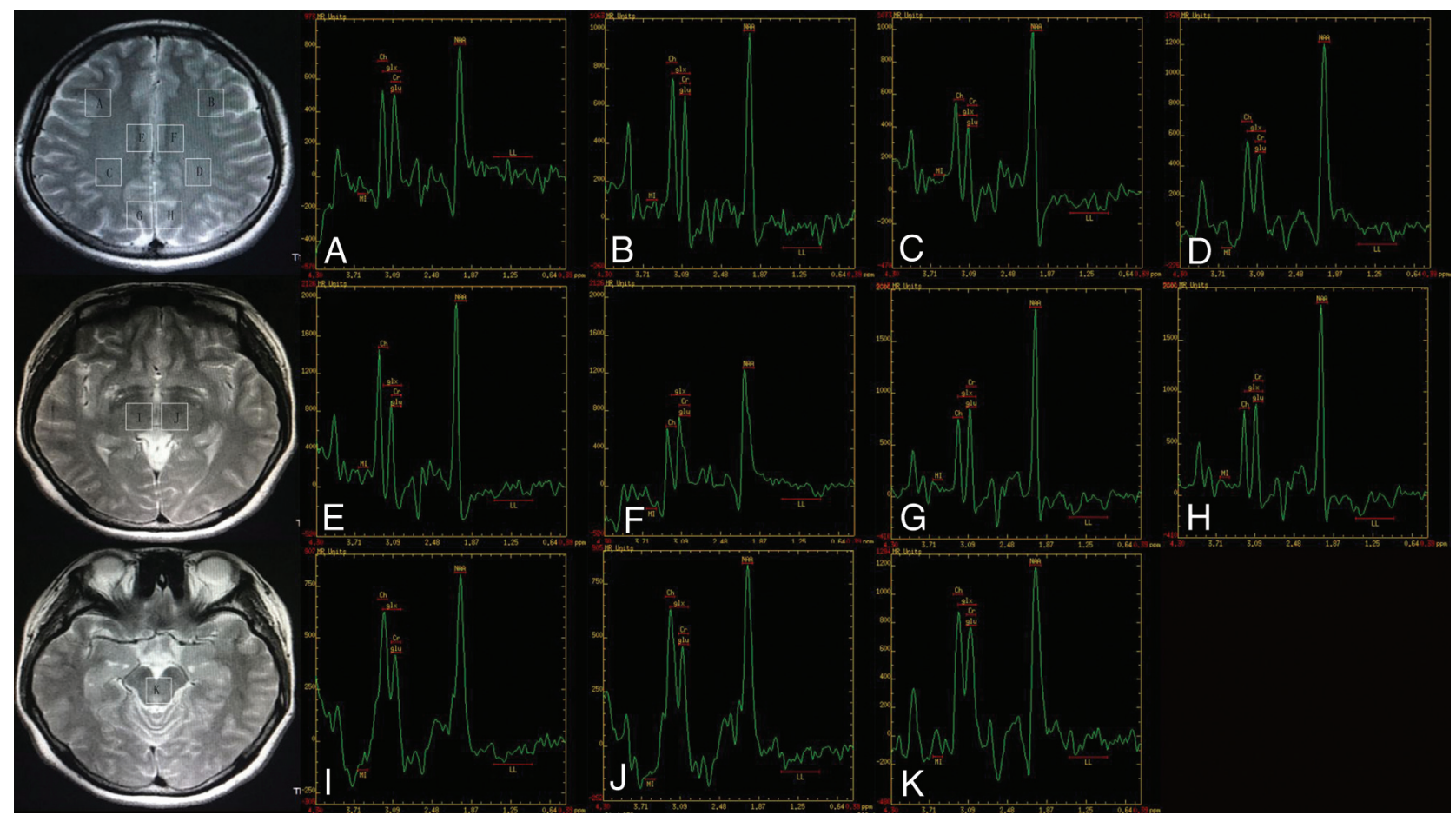

FIG 4. MR spectroscopy maps show the ROls including the bilateral inferior frontal $(A$ and $B)$, supramarginal gyrus $(C$ and $D)$, cingulate gyrus $(E$ and $F$ ), precuneus $(G$ and $H)$, thalamus ( $I$ and $J)$, and the upper brain stem $(K)$ of a healthy subject (control group).

subjects are shown in the Table. Significant differences were observed among the 4 groups with respect to the measured metabolite ratios in the thalamus and upper brain stem. The NAA/Cr ratio and NAA/ Cho + Cr ratio in the bilateral thalamus and upper brain stem in all patient groups were significantly lower than those in the control group (Figs 5 and 6). The Cho/Cr ratio in the right thalamus in the
FIAS group was significantly higher than that in the control group (Fig 7). No significant differences were observed among the 3 patient groups with respect to the metabolite ratios.

The SGTCS group showed a negative correlation between epilepsy duration and the NAA/ $(\mathrm{Cr}+\mathrm{Cho})$ ratio in the left $(P=.03)$ and right thalamus $(P=.04)$; however, no significant correlation 
between seizure frequency and metabolic alterations was observed in any of the patient groups ( $P>.05$ for both).

\section{DISCUSSION}

Multivoxel MR spectroscopy was used in the present study. Compared with single-voxel MR spectroscopy, disadvantages of multivoxel MR spectroscopy include the following: 1) relatively longer setup and scan time, 2) difficulties in obtaining homogeneous shim over the entire region, 3) lower signal-to-noise and spectral quality for individual voxels, and 4) spectral contamination from adjacent voxels. However, multivoxel MR spectroscopy offers higher spatial resolution and a larger total coverage area, which facilitate assessment of multiple regions of the brain at the same time. Therefore, multivoxel MR spectroscopy is more suitable for comparing metabolic alterations among different regions involved in the consciousness system, which conformed to the requirement of this study.

As in MR imaging, the TE affects the information obtained with MR spectroscopy. In general, long-TE methods could sup-

Demographic and clinical characteristics of subjects disaggregated by study group ${ }^{\text {a }}$

\begin{tabular}{lcccc}
\hline & FIAS & PGTCS & SGTCS & Control \\
\hline Age (yr) & $28 \pm 10$ & $26 \pm 10$ & $27 \pm 13$ & $27 \pm 9$ \\
Sex (M/F) & $14: 4$ & $10: 9$ & $13: 7$ & $16: 8$ \\
Duration of epilepsy (yr) & $8.25 \pm 7.85$ & $7.56 \pm 9.16$ & $6.18 \pm 7.57$ & - \\
Seizure frequency (No./yr) & $55 \pm 42$ & $15 \pm 25$ & $36 \pm 59$ & - \\
\hline
\end{tabular}

Note:-indicates there is no value.

${ }^{\text {a }}$ Data represented as mean $\pm S D$.
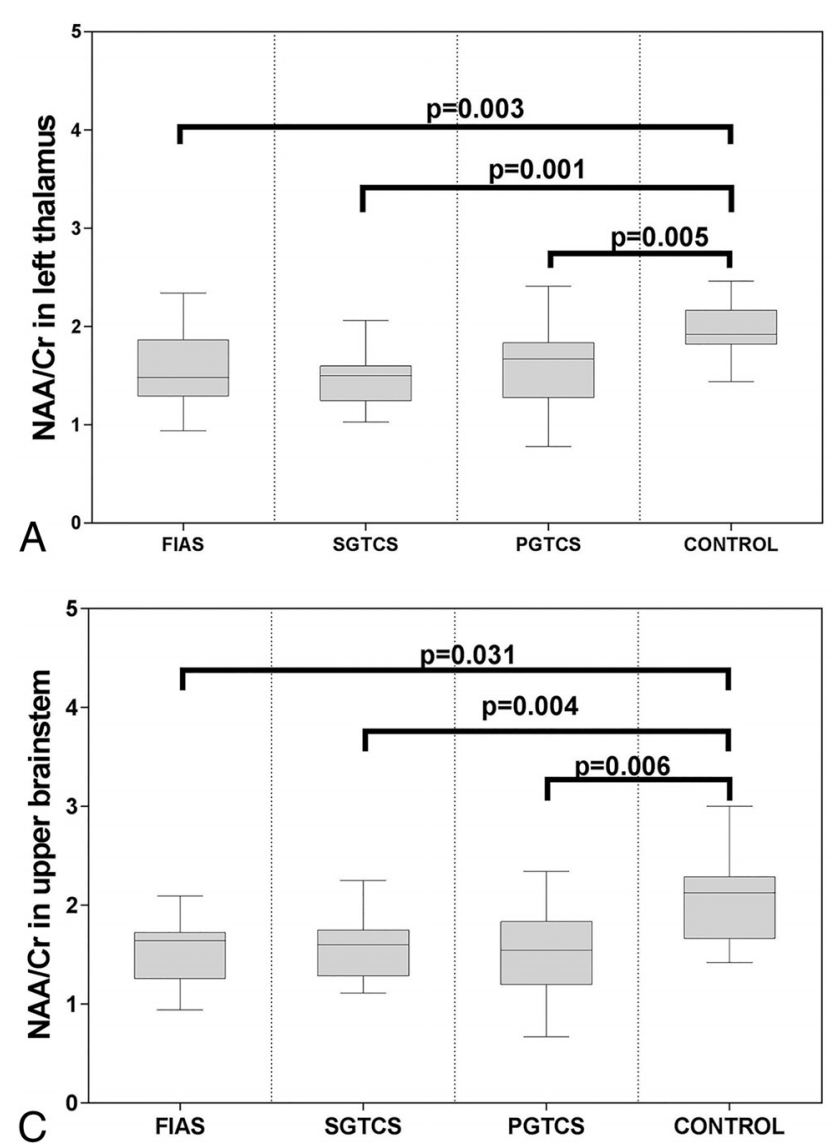

press short-T2 macromolecules and lipid signals, resulting in a more rectilinear baseline and more simplified spectra, which facilitate interpretation and quantitation of peak areas of major metabolites. ${ }^{23-25}$ Therefore, we used a long TE.

${ }^{1} \mathrm{H}$-MRS has been shown to be a reliable method for measurement of intracellular metabolite concentrations (eg, NAA, Cr, and Cho) in patients with epilepsy. ${ }^{13,26}$ Alterations in brain metabolite levels determined by ${ }^{1} \mathrm{H}$-MRS were shown to be consistent with the pathologic characteristics. ${ }^{27}$

The Cr peak in the ${ }^{1} \mathrm{H}$ spectrum represents both creatine and its phosphorylated form, phosphocreatine. These are found in high concentrations in metabolically active tissues such as the brain that produce energy by oxidative/aerobic metabolism. ${ }^{28} \mathrm{Cr}$ is a multifunctional molecule in the brain. It reflects energy metabolism and is particularly important for the maintenance of membrane potential. ${ }^{29,30}$ It is well-established that the level of $\mathrm{Cr}$ is relatively constant in the brain under physiologic conditions; therefore, it is often used as the internal concentration reference. ${ }^{15,20,31}$ While brain Cr concentration stays constant in many diseases, pathologic conditions that disturb cell energetics (such as stroke, tumors, and neurodegenerative diseases) may disturb the $\mathrm{Cr}$ concentration. ${ }^{31}$

The NAA level reflects the amount and functional metabolic status of neurons; its concentration decreases with neuronal damage and/or dysfunction. ${ }^{20,26}$ In the

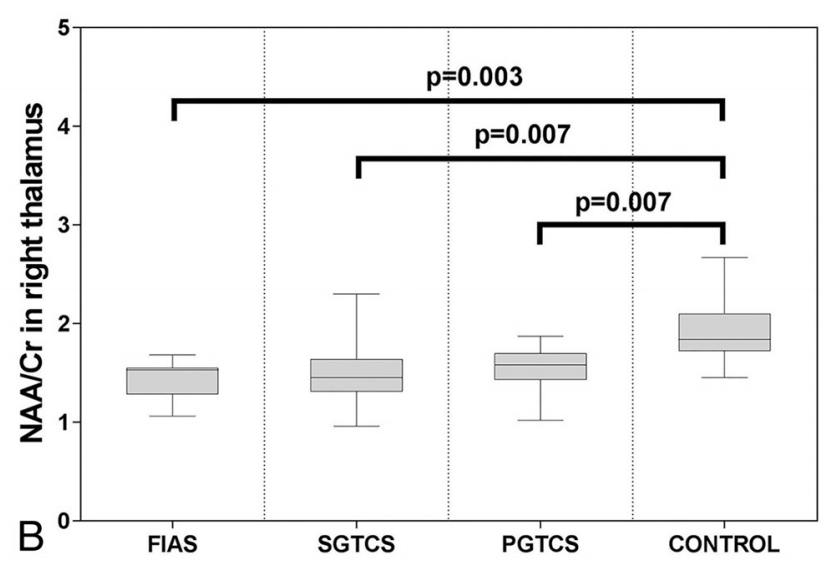

FIG 5. Boxplot for pair-wise comparison of ratios of NAA/Cr. Significant intergroup differences were observed in the bilateral thalamus ( $A$ and $B)$ and upper brain stem (C). 

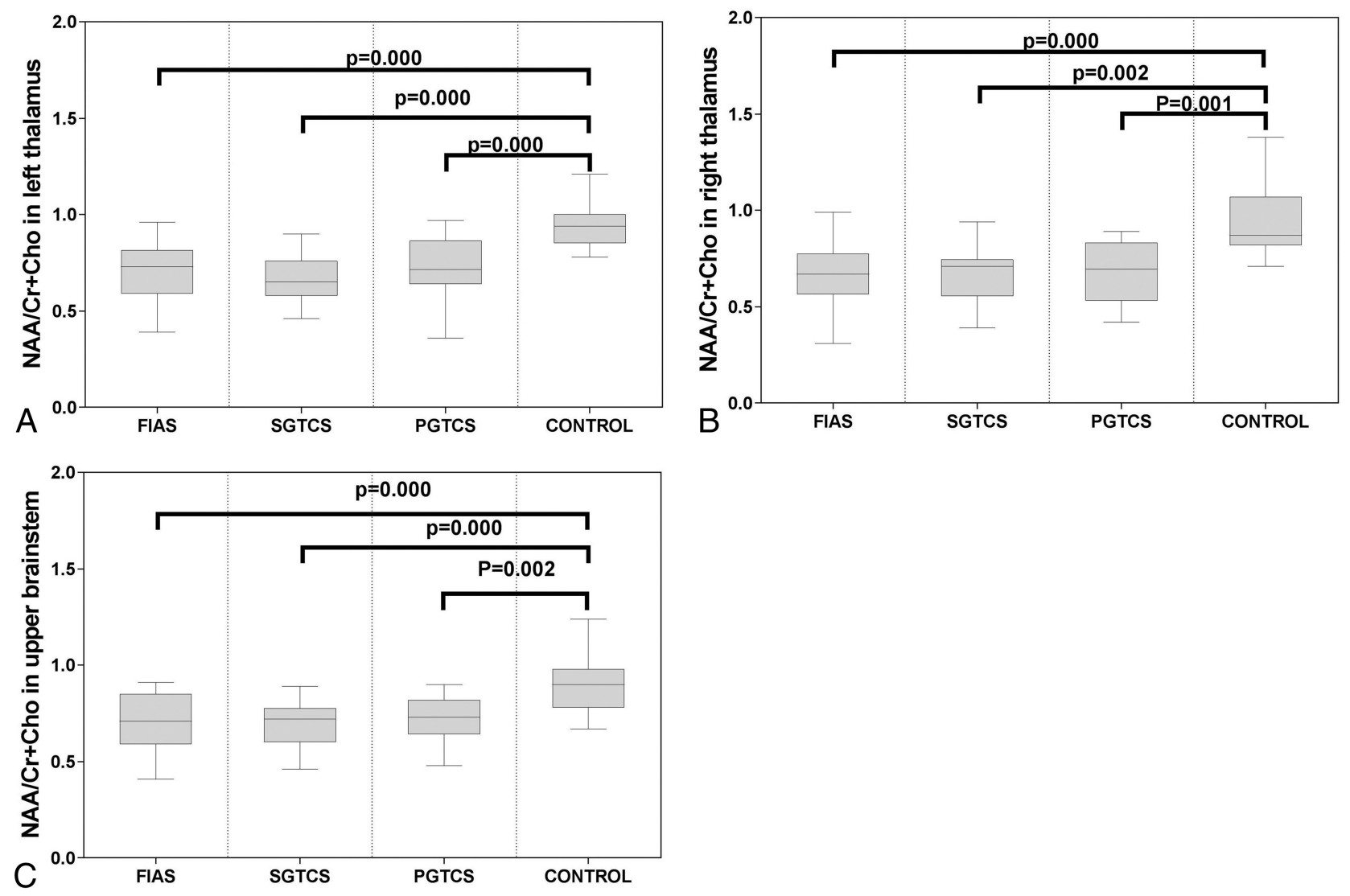

FIG 6. Boxplot for pair-wise comparison of ratios of $\mathrm{NAA} / \mathrm{Cr}+\mathrm{Cho}$. Significant intergroup differences were observed in the bilateral thalamus $(A$ and $B)$ and upper brain stem $(C)$.

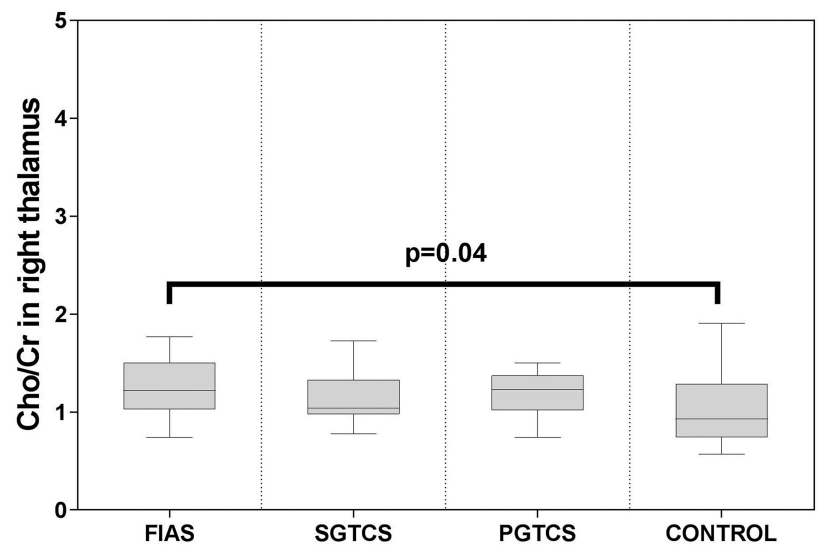

FIG 7. Boxplot for pair-wise comparison of ratios of Cho/Cr. Significant intergroup differences were observed in the right thalamus.

present study, importantly lower NAA/Cr and NAA/(Cr + Cho) ratios, which imply a decrease in the NAA level, were observed in the thalamus and upper brain stem in all 3 patient subgroups. Hammen et $\mathrm{al}^{21}$ and Hugg et $\mathrm{al}^{32}$ have already demonstrated the association of a reduced NAA level (as determined by ${ }^{1} \mathrm{H}-\mathrm{MR}$ spectroscopy) with neuronal loss in patients with temporal lobe epilepsy; these findings indicate that the NAA spectra is a valuable predictor of cell loss. Furthermore, Duc et $\mathrm{al}^{33}$ showed an association between altered NAA metabolism in mesial temporal lobe epilepsy and the degree of neuronal loss. However, Petroff et $\mathrm{al}^{34}$ found no significant association between hippocampal neuronal loss and the cellular content of NAA

and $\mathrm{Cr}$ in their ${ }^{1} \mathrm{H}-\mathrm{MR}$ spectroscopy study of hippocampal specimens; they proposed that neuronal dysfunction rather than neuronal loss results in a decrease in total NAA concentration due to mitochondrial damage. In a study by Dautry et $\mathrm{al}^{35}$ total NAA concentration was reduced by the mitochondrial toxin 3-nitropropionic acid in an animal model; however, no signs of neuronal cell degeneration or neuronal loss were observed in the subsequent postmortem histologic examination. On the basis of these findings, we speculate that there is neuronal loss or dysfunction in these regions. Further research is required to draw definitive conclusions in this respect.

In the present study, a significantly higher $\mathrm{Cho/Cr}$ ratio was observed in the right thalamus of patients in the PGTCS and FIAS groups. Cho content in the brain has been shown to mainly comprise free choline, glycerophosphocholine, and phosphocholine, ${ }^{36}$ which are markers of cell membrane integrity; their concentration increases in conditions that involve cell membrane turnover or destruction (eg, tumors and demyelinating diseases). ${ }^{20,29}$ However, Hammen et $\mathrm{al}^{21}$ characterized the metabolic alterations in the hippocampus of patients with temporal lobe epilepsy using single-voxel MR spectroscopy, and the alterations in Cho did not correlate with neuronal loss in any hippocampal subregion confirmed by neuropathology. Whether an increase in the Cho/Cr ratio may indicate neuronal loss is open to debate and further research.

Consistent with this observation, previous DTI studies have shown significantly higher ADC values in the bilateral thalamus 
and upper brain stem in patients with FIAS, PGTCS, and SGTCS; these findings indicate neuronal dysfunction in the bilateral dorsal thalamus and upper brain stem of these patients. ${ }^{11}$ This conclusion is consistent with those of previous studies that showed that neuronal damage or dysfunction of the thalamus and upper brain stem may impair consciousness. ${ }^{37,38}$ Regardless of the seizure type, metabolite alterations are observed in common specific regions of the brain, which indicate their involvement in the mechanism of a variety of seizures with conscious disturbance.

However, there was no significant metabolic alteration in regions other than the bilateral thalamus and upper brain stem in all experimental groups. Compared with the spectra from voxels that cover the bilateral thalamus and upper brain stem, the spectra from other voxels are more susceptible to contamination from CSF and white matter around other ROIs, which may affect the accuracy of spectra from those voxels; this may have resulted in the observed lack of a significant metabolic alteration.

Several previous studies have described a correlation between structural abnormalities of the hippocampus and the duration of epilepsy in patients with temporal lobe epilepsy ${ }^{39,40}$; this indicates that repeat seizures cause progressive damage to specific regions. Therefore, it is conceivable that patients with a longer duration of epilepsy and more frequent seizures have more severe metabolic abnormalities. Indeed, epilepsy duration and seizure frequency were shown to be associated with the level of NAA in the temporal lobe in previous studies focused on temporal lobe epilepsy. ${ }^{41,42}$ Consistent with this finding, we found a significant inverse correlation between epilepsy duration and the $\mathrm{NAA} /(\mathrm{Cr}+\mathrm{Cho})$ ratio in the bilateral thalamus in the SGTCS group, but not in the FIAS group. In the present study, seizure frequency was not a significant predictor of the degree of metabolic abnormality; however, the lack of association may be attributable to the small sample size. Thus, the association between seizure frequency and the degree of metabolic abnormality requires further study involving a larger cohort of patients.

In several previous studies, the influence of antiepileptic drugs was analyzed. However, no statistically significant effects of antiepileptic drugs were found in most previous studies. Simister et $\mathrm{al}^{13}$ found no significant difference in gamma-aminobutyric acid plus homocarnosine values between patients with idiopathic generalized epilepsy receiving antiepileptic drugs and those not receiving antiepileptic drugs. Lin et $\mathrm{al}^{14}$ found no significant effects of medication on NAA/Cr. Whether antiepileptic drugs have an effect on alterations in brain metabolites is open to debate and further research.

In the present study, significantly lower NAA/Cr and NAA/ $(\mathrm{Cr}+\mathrm{Cho})$ ratios were observed in the thalamus in all patient groups, while a significantly high Cho/Cr ratio was only observed in the right thalamus $(P<.05)$ in the FIAS group. However, when patients with PGTCS were compared with healthy subjects, a trend toward higher values of $\operatorname{Cho} / \mathrm{Cr}(P=.06)$ was observed in the PGTCS group. In addition, previous studies that focused on idiopathic generalized epilepsy or generalized tonic-clonic seizures have demonstrated the thalamic metabolic abnormalities using ${ }^{1} \mathrm{H}$-MRS. ${ }^{43,44}$ These findings indicate that the thalamus may be involved in the underlying mechanism of impaired con- sciousness in all forms of epilepsy that were studied in our research.

Several studies have described a relationship between structural abnormalities and the duration of epilepsy. ${ }^{39,41}$ In addition, previous neuroimaging studies have reported a negative association between epilepsy duration and thalamic NAA/Cr ratios. ${ }^{14,43}$ It could be expected that patients with a longer duration of epilepsy may show more severe metabolic abnormalities. However, our data failed to show any association between thalamic metabolic alterations and epilepsy duration in any of the groups except the SGTCS group. It will therefore be necessary to replicate the findings in a larger population.

Some limitations of our study should be noted. These include the single-center design, small sample size, and heterogeneity among the patient groups with respect to antiepileptic treatment and the interval between the last known seizure and the scan. These limitations may have impacted the results such as the observed lack of correlation between seizure frequency and metabolic alterations. Use of FuncTool to analyze the data is suboptimal; a more sophisticated approach such as the LCModel (http:// www.s-provencher.com/lcmodel.shtml) would be preferable because it also includes uncertainty estimates. $\mathrm{Cr}$ or $\mathrm{Cr}+\mathrm{Cho}$ concentrations were used as an internal concentration reference to simplify quantification; however, it is difficult to rule out the possibility that the metabolic abnormalities were due to elevated $\mathrm{Cr}$ and/or Cho concentrations rather than to the reduced NAA concentration. Therefore, an alternative would be to use water concentration as an internal reference in further research. A small proportion of the data were from the edge of the volume, which may have impacted the accuracy of the spectra.

Further studies are required to examine the pre- and posttreatment metabolic alterations in epilepsy associated with loss of consciousness and to determine the influence of other factors on metabolic alterations in regions associated with loss of consciousness (eg, the type of antiepileptic drug and the interval between the last seizure and the scan).

\section{CONCLUSIONS}

${ }^{1} \mathrm{H}$-MRS is a noninvasive neuroradiology technique that is more sensitive than routine brain MR imaging for the detection of metabolic alterations in patients with epilepsy. Our research demonstrated altered levels of NAA and Cho in the thalamus and upper brain stem of patients with epilepsy, which is indicative of neuronal dysfunction and/or neuronal loss. Neuronal dysfunction in these areas may contribute to the loss of consciousness in these patients. Furthermore, patients with a longer duration of epilepsy may have more severe metabolic abnormalities.

\section{ACKNOWLEDGMENTS}

We thank all our colleagues at the Department of Radiology for the permission to use GE Signa HDX 3T MR imaging scanner.

\section{REFERENCES}

1. Sperling MR. The consequences of uncontrolled epilepsy. CNS Spectr 2004;9:98-101, 106-09 Medline

2. Vickrey BG, Berg AT, Sperling MR, et al. Relationships between seizure severity and health-related quality of life in refractory localization-related epilepsy. Epilepsia 2000;41:760-64 CrossRef Medline 
3. Bagshaw AP, Cavanna AE. Brain mechanisms of altered consciousness in focal seizures. Behav Neurol 2011;24:35-41 CrossRef Medline

4. Cavanna AE, Monaco F. Brain mechanisms of altered conscious states during epileptic seizures. Nat Rev Neurol 2009;5:267-76 CrossRef Medline

5. Seri S, Brazzo D, Thai NJ, et al. Brain mechanisms of altered consciousness in generalised seizures. Behav Neurol 2011;24:43-46 CrossRef Medline

6. Blumenfeld H. Impaired consciousness in epilepsy. Lancet Neurol 2012;11:814-26 CrossRef Medline

7. Yu L, Blumenfeld $\mathrm{H}$. Theories of impaired consciousness in epilepsy. Ann of N Y Acad Sci 2009;1157:48-60 CrossRef Medline

8. Blumenfeld H. Epilepsy and the consciousness system: transient vegetative state? Neurol Clin 2011;29:801-23 CrossRef Medline

9. Blumenfeld H, McNally KA, Vanderhill SD, et al. Positive and negative network correlations in temporal lobe epilepsy. Cereb Cortex 2004;14:892-902 CrossRef Medline

10. Lee KH, Meador KJ, Park YD, et al. Pathophysiology of altered consciousness during seizures: subtraction SPECT study. Neurology 2002;59:841-46 CrossRef Medline

11. Marie A, Luc V, Jean R, et al. Impaired consciousness during temporal lobe seizures is related to increased long-distance corticalsubcortical synchronization. Brain 2009;132:2091-101 CrossRef Medline

12. Xie F, Xing W, Wang X, et al. Altered states of consciousness in epilepsy: a DTI study of the brain. Int J Neurosci 2017;127:667-72 CrossRef Medline

13. Simister RJ, McLean MA, Barker GJ, et al. A proton magnetic resonance spectroscopy study of metabolites in the occipital lobes in epilepsy. Epilepsia 2003;44:550-58 CrossRef Medline

14. Lin K, Carrete H Jr, Lin J, et al. Magnetic resonance spectroscopy reveals an epileptic network in juvenile myoclonic epilepsy. Epilepsia 2009;50:1191-200 CrossRef Medline

15. Mueller SG, Ebel A, Barakos J, et al. Widespread extrahippocampal $\mathrm{NAA} /(\mathrm{Cr}+\mathrm{Cho})$ abnormalities in TLE with and without mesial temporal sclerosis. J Neurol 2011;258:603-12 CrossRef Medline

16. Kabay SC, Gumustas OG, Karaman HO, et al. A proton magnetic resonance spectroscopic study in juvenile absence epilepsy in early stages. Eur J Paediatr Neurol 2010;14:224-28 CrossRef Medline

17. Striano P, Caranci F, Di Benedetto R, et al. (1)H-MR spectroscopy indicates prominent cerebellar dysfunction in benign adult familial myoclonic epilepsy. Epilepsia 2009;50:1491-97 CrossRef Medline

18. de Araüjo Filho GM, Lin K, Lin J. Are personality traits of juvenile myoclonic epilepsy related to frontal lobe dysfunctions? A proton MRS study. Epilepsia 2009;50:1201-09 CrossRef Medline

19. Hajek M, Dezortova M, Krsek P, et al. (1)H MR spectroscopy in epilepsy. Eur J Radiol 2008;67:258-67 CrossRef Medline

20. McLean MA, Cross JJ. Magnetic resonance spectroscopy: principles and applications in neurosurgery. Br J Neurosurg 2009;23:5-13 Medline

21. Hammen T, Hildebrandt M, Stadlbauer A, et al. Non-invasive detection of hippocampal sclerosis: correlation between metabolite alterations detected by (1)H-MRS and neuropathology. NMR Biomed 2008;21:545-52 CrossRef Medline

22. Fisher RS, Cross JH, French JA, et al. Operational classification of seizure types by the International League Against Epilepsy: Position Paper of the ILAE Commission for Classification and Terminology. Epilepsia 2017;58:522-30 CrossRef Medline

23. Hancu I, Zimmerman EA, Sailasuta N, et al. 1H-MR spectroscopy using TE averaged PRESS: a more sensitive technique to detect neurodegeneration associated with Alzheimer's disease. Magn Reson Med 2005;53:777-82 CrossRef Medline

24. Hurd R, Sailasuta N, Srinivasan R, et al. Measurement of brain glu- tamate using TE-averaged PRESS at 3T. Magn Reson Med 2004;51: 435-40 CrossRef Medline

25. Cendes F, Knowlton RC, Novotny E. Magnetic resonance spectroscopy in epilepsy: clinical issues. Epilepsia 2002;43(Suppl 1):32-39

26. Xu M, Ergene E, Zagardo M, et al. Proton MR spectroscopy in patients with structural MRI-negative temporal lobe epilepsy. J Neuroimaging 2015;25:1030-37 CrossRef Medline

27. Maton BM, Kuzniecky RI. Proton MRS: $\mathrm{N}$-acetyl aspartate, creatine, and choline. Adv Neurol 2000;83:253-59 Medline

28. Stovell MG, Yan JL, Sleigh A, et al. Assessing metabolism and injury in acute human traumatic brain injury with magnetic resonance spectroscopy: current and future applications. Front Neurol 2017;8: 426 CrossRef Medline

29. Wyss M, Kaddurah-Daouk R. Creatine and creatinine metabolism Physiol Rev 2000;80:1107-213 CrossRef Medline

30. Béard E, Braissant O. Synthesis and transport of creatine in the CNS importance for cerebral functions. J Neurochem 2010;115:297-313 CrossRef Medline

31. Rackayova V, Cudalbu C, Pouwels PJ, et al. Creatine in the central nervous system: from magnetic resonance spectroscopy to creatine deficiencies. Anal Biochem 2017;529:144-57 CrossRef Medline

32. Hugg JW, Laxer KD, Matson GB, et al. Neuron loss localizes human temporal lobe epilepsy by in vivo proton magnetic resonance spectroscopic imaging. Ann Neurol 1993;34:788-94 CrossRef Medline

33. Duc CO, Trabesinger AH, Weber OM, et al. Quantitative 1H MRS in the evaluation of mesial temporal lobe epilepsy in vivo. Magn Reson Imaging 1998;16:969-79 CrossRef Medline

34. Petroff OA, Errante LD, Kim JH, et al. N-acetyl-aspartate, total creatine, and myo-inositol in the epileptogenic human hippocampus. Neurology 2003;60:1646-51 CrossRef Medline

35. Dautry C, Vaufrey F, Brouillet E, et al. Early N-acetyl aspartate depletion is a marker of neuronal dysfunction in rats and primates chronically treated with the mitochondrial toxin 3-nitropropionic acid. J Cereb BloodFlow Metab 2000;20:789-99 CrossRef Medline

36. Barker PB, Breiter SN, Soher BJ, et al. Quantitative proton spectroscopy of canine brain: in vivo and in vitro correlations. Magn Reson Med 1994;32:157-63 CrossRef Medline

37. Greenberg MK, Barsan WG, Starkman S. Neuroimaging in the emergency patient presenting with seizure. Neurology 1996;47:26-32 CrossRef Medline

38. Greicius MD, Krasnow B, Reiss AL, et al. Functional connectivity in the resting brain: a network analysis of the default mode hypothesis. Proc Natl Acad Sci U S A 2003;100:253-58 CrossRef Medline

39. McDonald CR, Hagler DJ Jr, Ahmadi ME, et al. Regional neocortical thinning in mesial temporal lobe epilepsy. Epilepsia 2008;49:794803 CrossRef Medline

40. Coan A, Appenzeller S, Bonilha L, et al. Seizure frequency and lateralization affect progression of atrophy in temporal lobe epilepsy. Neurology 2009;73:834-42 CrossRef Medline

41. Garcia PA, Laxer KD, van der Grond J, et al. Correlation of seizure frequency with $\mathrm{N}$-acetyl-aspartate levels determined by $1 \mathrm{H}$ magnetic resonance spectroscopic imaging. Magn Reson Imaging 1997; 15:475-78 CrossRef Medline

42. Tasch E, Cendes F, Li L, et al. Neuroimaging evidence of progressive neuronal loss and dysfunction in temporal lobe epilepsy. Ann Neurol 1999;45:568-76 CrossRef Medline

43. Bernasconi A, Bernasconi N, Natsume J, et al. Magnetic resonance spectroscopy and imaging of the thalamus in idiopathic generalized epilepsy. Brain 2003;126:2447-54 CrossRef Medline

44. Haki C, Gümüştaş OG, Bora I, et al. Proton magnetic resonance spectroscopy study of bilateral thalamus in juvenile myoclonic epilepsy. Seizure 2007;16:287-95 CrossRef Medline 